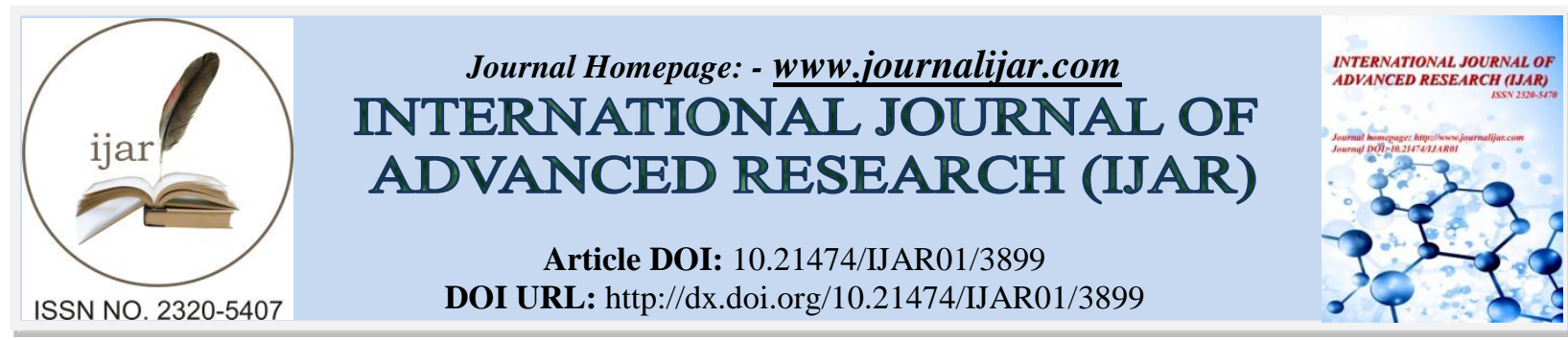

RESEARCH ARTICLE

\title{
HOLLOW SPEECH BULB IN COMPLETELY EDENTULOUS PATIENT: A CASE REPORT.
}

\section{Dr. Amrita Phurailatpam ${ }^{1}$, Dr. Dhakshaini.M.R ${ }^{2}$, Dr. Raghavendra Swamy K. $\mathbf{N}^{3}$ and \\ Dr.Anil Kumar Gujjari ${ }^{4}$.}

1. Final year post graduate student in the Department of Prosthodontic, Crown and Bridge, Jagadguru Sri Shivarathreeshwara Dental College, Jagadguru Sri Shivarathreeshwara University, Mysuru-570015, Karnataka, India.

2. Head of Department and Professor in the Department of Prosthodontic, Crown and Bridge, Jagadguru Sri Shivarathreeshwara Dental College, Jagadguru Sri Shivarathreeshwara University, Mysuru-570015, Karnataka, India.

3. Professor in the Department of Prosthodontic, Crown and Bridge, Jagadguru Sri Shivarathreeshwara Dental College, Jagadguru Sri Shivarathreeshwara University, Mysuru-570015, Karnataka, India.

4. Principal \&Professor in the Department of Prosthodontic, Crown and Bridge, Jagadguru Sri Shivarathreeshwara Dental College, Jagadguru Sri Shivarathreeshwara University, Mysuru-570015, Karnataka, India.

\section{Manuscript Info}

(.........................

Manuscript History

Received: 16 February 2017

Final Accepted: 17 March 2017

Published: April 2017

Key words:-

Speech bulb, velopharyngeal incompetence, hypernasality

\section{Abstract}

Hypernasality and nasal regurgitation of food and liquids are the common problems associated with vasopharyngeal insufficiency. Surgery is the preferred treatment for soft palate defect but for those patients who cannot undergo surgical treatment, prosthetic treatment combined with speech therapy is the treatment of choice. It is a prosthodontic challenge to rehabilitate a patient with partial resection of soft palate. This clinical report describes the prosthetic rehabilitation of a completely edentulous patient who had undergone surgical resection of soft palate due to squamous cell carcinoma with a hollow speech aided complete denture prosthesis.

Copy Right, IJAR, 2017,. All rights reserved.

\section{Introduction:-}

The movable posterior portion of the palate, the soft palate marks the beginning of the oropharynx. Defects of the soft palate can be congenital, acquired or developmental. In the congenital cleft palate the embryological development of the hard and /or soft palate is interrupted. Surgical resection of neoplastic disease can alter the continuity the soft palate resulting in an acquired defect. Occasionally palatal defect emergence from damage to the central nervous system e.g. cerebral palsy, amytrophic lateral sclerosis, poliomyelitis,myasthenia gravis, or myotonic dystrophy ( Chalian,1972). Diminished capacity of the soft palate can affect oral activities such as speech, swallowing, blowing, sucking, and whistling which are regulated by the palatopharyngeal or velopharyngeal valving mechanism (Knowles et.al, 1984; Davis JW et al, 1987)

Rehabilitation of a patient with partial resection present as perplexing problem to the clinician. As a general rule, palatopharyngeal insufficiency is treated with a pharyngeal bulb prosthesis commonly known as speech bulb and palatopharyngeal incompetence is treated with palatal lift.

Corresponding Author:- Dr. Amrita Phurailatpam.

Address:- Final year post graduate student in the Department of Prosthodontic, Crown and Bridge, Jagadguru Sri Shivarathreeshwara Dental College, Jagadguru Sri Shivarathreeshwara University, Mysuru570015, Karnataka, India. 


\section{Case report:-}

A 64 year old male patient reported to the Department of Prosthodontics, Crown and Bridge, Jagadguru Sri Shivarathreeshwara Dental College, Jagadguru Sri Shivarathreeshwara University, Mysuru with a chief complaint of difficulty in swallowing. History revealed that patient had undergone surgical resection of soft palate due to squamous cell carcinoma 5 months back followed by radiotherapy. Intraoral examination reveal completely edentulous maxillary and mandibular arch, and soft palatal defect due to surgical excision of tumor (Fig. 1). The size of the defect measured around $3 \mathrm{~cm} \times 3 \mathrm{~cm}$ in diameter. Hypernasality of speech was present. A complete denture with speech bulb was planned for the patient since he exhibited symptoms of velopharangeal dysfunction. The treatment procedure was explained to the patient and his relative (brother) and their consent was obtained.

\section{Primary impression:-}

Patient was seated in an upright position and properly draped. To ensure that the impression material doesn't flow into the hypopharynx of the patient, one dental assistant was asked to stand by with a high speed suction during the procedure. A stock maxillary tray of proper size was selected, the borders and the posterior aspect of the tray was lined with utility wax to confine the impression material. The soft palate defect was rinsed with saline and blocked with iodine dipped gauge. Primary impression of the maxillary arch was made using irreversible hydrocolloid (Algitex, DPI, India) . Mandibular primary impression was made in the conventional method. The impressions were poured with dental plaster and the primary cast was obtained. Undercut was blocked on the primary cast and custom tray extending till the defect was fabricated using autopolymerising acrylic resin ( DPI, India ).

\section{Final impression:-}

Border moulding was done and the area of the defect was functionally molded using low fusing green stick compound (Fig.2). Final impression was made using light body (3M ESPE EXPRESS) (Fig.3) and the impression was poured using dental stone. The master cast was duplicated. Denture base that extend upto posterior palatal area was fabricated. Jaw relation, teeth setting was done.

\section{Retentive wires:-}

2 lines was drawn on the dulicated master cast using a pencil starting from the posterior aspect of the hard palate till the anterior aspect of the soft palate defect. Orthodontic wire was adapted on the pencil marking. The flexibility of the wire allowed the movement of the part of prosthesis extending till the soft palate defect. This wire was attached to the posterior part of the trial denture approximating the soft palate defect (Fig.4).

\section{Funtional impression of the defect:-}

The patient was called on the next appointment to make the functional impression of the contours of the defect. Low fusing green stick compound was added on the retentive loop. The patient was advised to turn his head to the right and left sides, make circular head movements, speak, swallow to record the contours of the defect can be recorded. The final impression was made using light body ( Fig.5).

Speech was evaluated for the patient. The insufficient nasal resonance was checked by asking the patient to say the three consonants ' $m$ ', ' $n$ ', 'ng'. The retentive loop was cut from the trial denture to separate the functional impression of the defect. Cast was poured for the functional impression of the defect using dental stone to form a bulb. Investment was done separately for the complete denture and the speech bulb. The bulb was made hollow using lost salt technique to make the prosthesis lighter. The duplicated master cast was used to aligned and attach the speech bulb to the complete denture using $0.8 \mathrm{~mm}$ stainless steel wire with the help of self cure resin. This allowed the movement of the speech bulb ( Fig 6). Insertion was done (Fig 7) and post insertion instructions were given. Patient was recalled for followed up one day and one week after the insertion. Patient was referred to speech pathologist. 


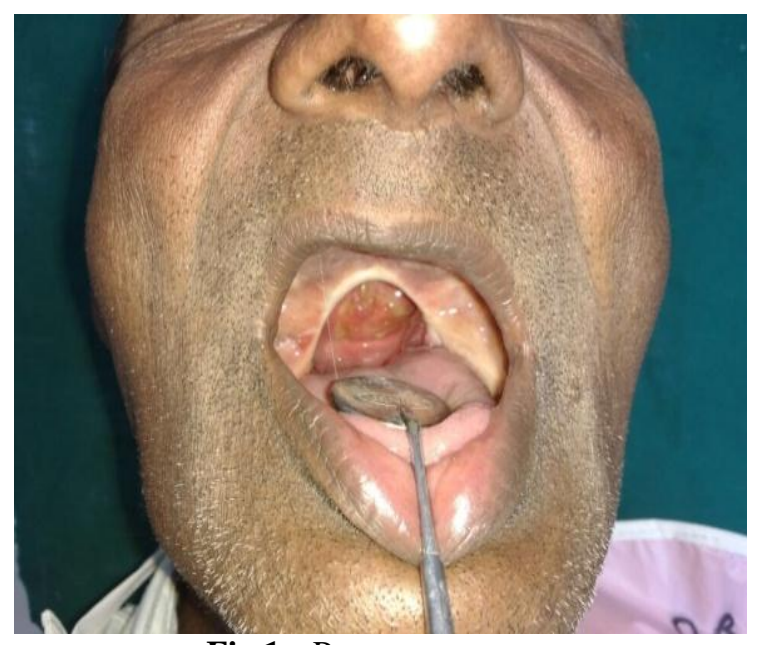

Fig.1:- Pre op.

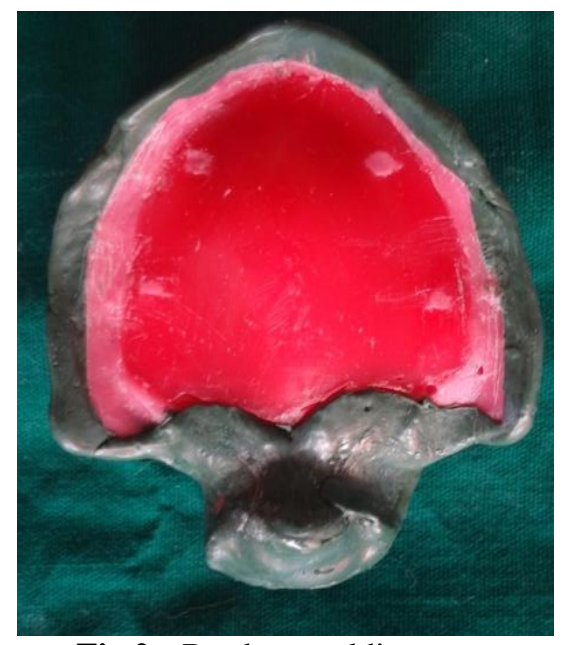

Fig.2:- Border moulding.

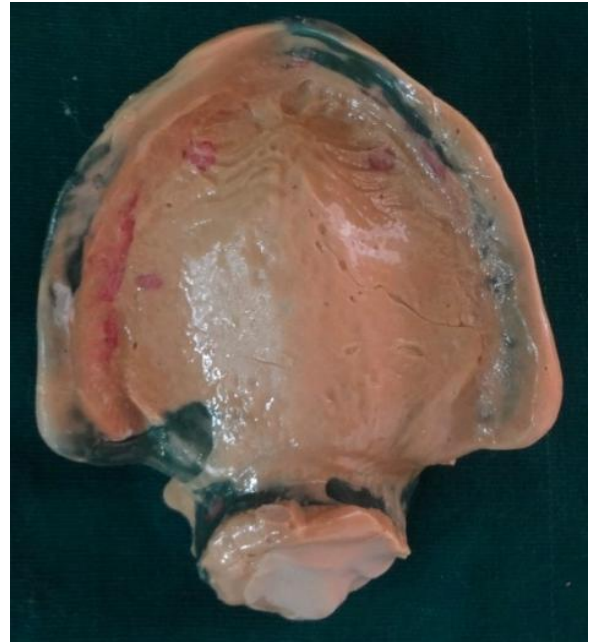

Fig.3:- Final impression.

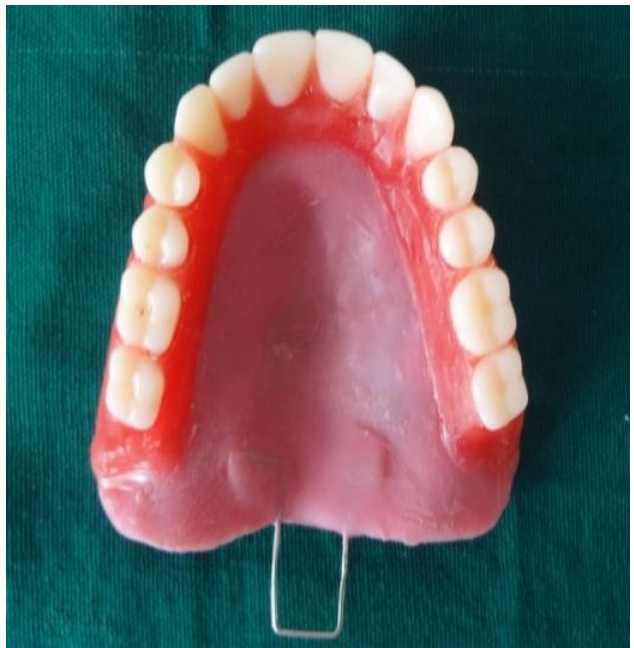

Fig. 4:- Retentive wire.

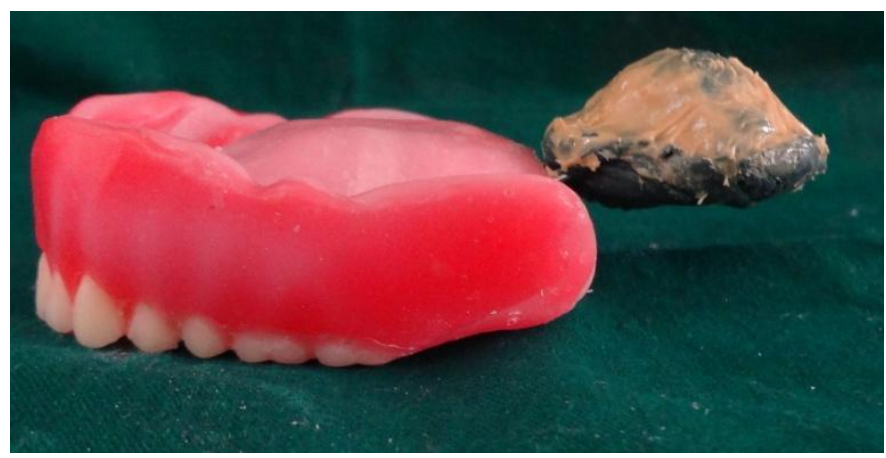

Fig 5:-.Functional impression of the defect. 


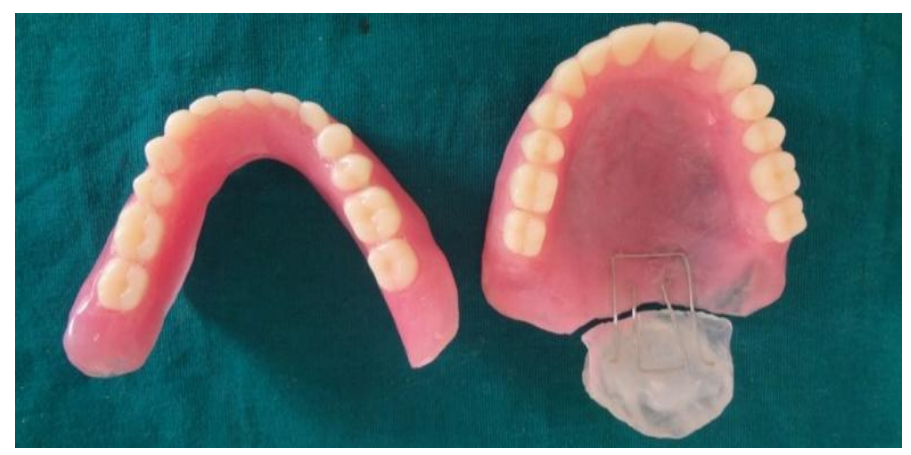

Fig. 6.:-Prosthesis.

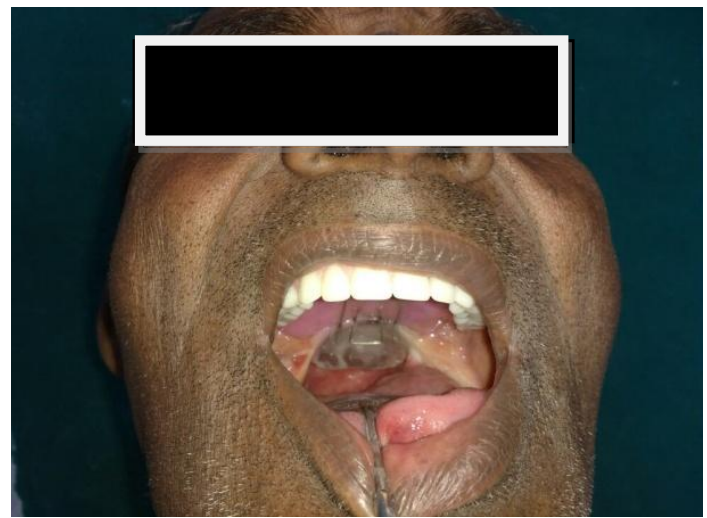

Fig.7:- Post op.

\section{Discussion:-}

Proper function of velopharyngeal mechanism is required for normal oronasal respiration control, speech, swallowing, blowing, sucking, whistling, and sneezing (Rodenstein D.O, Stanescu DC, 1986; Shprintzen RJ et.al, 1975). For the correction of speech in patients affected by velopharyngeal dysfunction, surgery is the preferred treatment. But it may not be always feasible owing to patients systemic condition. So for the patients who cannot undergo surgical treatment, prosthodontic rehabilitation and speech therapy is the treatment of choice. A speech pathologist should examine these cases to test inappropriate oro-nasal resonance balance, articulation, substitutions, omissions.

It is difficult to achieve an effective retention by conventional prostheses for the edentulous patients with both hard and soft palate defects ( Abreu et.al, 2007; Lefkove et.al, 2013; Lund, Wade, 1993).This is because of the weight of the prosthesis and the inability to obtain a border seal ( Harrison JW, 1992). In this case, the weight of the bulb was reduce by making it hollow. The success of the soft palate defect prosthesis depends on the functional adaptation of the impression material (Key.F et.al, 2013; Abreu et.al, 2013). In this case, proper functional adapation was obtain using low fusing green stick compound and light body. Many types of speech-bulb prostheses have been used to aid in velopharyngeal insufficiency : hinge type,meatus-type obturator( Taylor TD, Desjardin RP,1983), palatal lift prosthesis devices ( Lang BR, Kipfmueller LJ, 1969), palatal stimulators, and fixed-type obturator known as a speech bulb( Mazaheri M, Mazaheri EH, 1976). Here the movable type speech bulb was used.

\section{Conclusion:-}

For patient having soft palate defect that cannot be managed with surgical treatment, prosthetic treatment in combination with speech therapy is the treatment of choice. The contours of soft palatal defect should be carefully recorded to obtain an effective nasopharymgeal obturation. Fabrication of the prosthesis following proper speech evaluation will definitely improve the quality of life of the patient. 


\section{Reference:-}

1. Abreu A, Levy D, Rodriguez E, et al. Oral rehabilitation of a patient with complete unilateral cleft lip and palate using implant-retained speech-aid prosthesis: clinical report. Cleft Palate Craniofac J 2007;2013:673-7.

2. Abreu A, Levy D, Rodriguez E, et al. Oral rehabilitation of a patient with complete unilateral cleft lip and palate using implant-retained speech-aid prosthesis: clinical report. Cleft Palate Craniofac J 2007;2013:673-7.

3. Chelian VA, Drane JB, Standish SM. Maxillofacial prosthesis: Multidisciplinary practice. Williams \& Wilkins Co., 1972 .

4. Davis JW, Lazarus C, Logemann J, Hurst PS. Effect of a maxillary glossectomy prosthesis on articulation and swallowing. The Journal of prosthetic dentistry. 1987;57(6):715-9.

5. Harrison JW. Dental implants to rehabilitate a patient with an unrepaired complete cleft of the hard and soft palate: a clinical report. Cleft Palate Craniofac J 1992;2013:485-8.

6. Keyf F, Sahin N, Aslan Y. Alternative impression technique for a speech-aid prosthesis. Cleft Palate Craniofac J 2003;2013:566-8.

7. Knowles JC, Chalian VA, Shanks JC. A functional speech impression used to fabricate a maxillary speech prosthesis for a partial glossectomy patient. J Prosthet Dent 1984;51:232-7 8.Lang BR, Kipfmueller LJ. Treating velopharyngeal inadequacy with the palatal lift concept. Plastic and reconstructive surgery. 1969;43(5):467-77.

8. Lefkove MD, Matheny B, Silverstein L. Implant prosthodontic procedures for a completely edentulous patient with cleft palate. J Oral Implantol 1994;2013:82-9.

9. Lund TW, Wade M. Use of osseointegrated implants to support a maxillary denture for a patient with repaired cleft lip and palate. Cleft Palate Craniofac J 1993;2013:418-20.

10. Mazaheri M, Mazaheri EH. Prosthodontic aspects of palatal elevation and palatopharyngeal stimulation. The Journal of prosthetic dentistry. 1976;35(3):319-26.

11. Rodenstein DO, Stanescu DC. The soft palate and breathing. The American review of respiratory disease. 1986;134(2):311-25.

12. Shprintzen RJ, McCall GN, Skolnick ML, Lencione RM. Selective movement of the lateral aspects of the pharyngeal walls during velopharyngeal closure for speech, blowing, and whistling in normals. The Cleft palate journal. 1975;12(00):51-8.

13. Taylor TD, Desjardins RP. Construction of the meatus-type obturator: its advantages and disadvantages. The Journal of prosthetic dentistry. 1983;49(1):80-4. 